\title{
Avaliação de uma Solução Baseada em Fog Computing para a
}

\section{Pecuária Leiteira de Precisão}

\author{
Márcio Spenst ${ }^{1}$, Renata W. Suñé ${ }^{2}$, Marcos J. Yokoo ${ }^{1,2}$, Leonardo B. Pinho ${ }^{1}$ \\ ${ }^{1}$ Programa de Pós-Graduação em Computação Aplicada - UNIPAMPA - Bagé - RS, \\ marciospenst@ifsul.edu.br, leonardopinho@unipampa.edu.br \\ ${ }^{2}$ Unidade Pecuária Sul - EMBRAPA - Bagé - RS, renata.sune@embrapa.br, \\ marcos.yokoo@embrapa.br
}

Resumo. O trabalho apresenta a concepção de um modelo de sistema computacional escalável e distribuído, aplicado à gestão e qualificação de processos existentes na cadeia do leite. Baseado em uma arquitetura cloudfog-thing, de baixo custo, instalados no sistema de ordenha, compostos por sensores e atuadores, capazes de se comunicar, com dispositivos móveis de capacidade intermediária presentes na camada "fog", explorando mecanismos de comunicação veicular entre as diferentes camadas.

\section{Introdução}

Recentemente a Instrução Normativa (IN) 76/2018, a qual regulamenta a qualidade de leite cru refrigerado, determinou que no momento do recebimento do leite no laticínio a temperatura do mesmo deve estar em $7{ }^{\circ} \mathrm{C}$, sendo que anteriormente a temperatura aceita era de $10{ }^{\circ} \mathrm{C}$, excepcionalmente admitindo o recebimento com até $9{ }^{\circ} \mathrm{C}$ [MAPA, 2018, a]. Por outro lado a Instrução Normativa 77/2018, regulamenta que o leite ordenhado e armazenado em tanque de expansão direta, deve atingir a temperatura de 4 ${ }^{\circ} \mathrm{C}$ em até 3 horas após a ordenha. Além disso, regulamenta que o leite estocado nos tanques de refrigeração deve ser amostrado pelo responsável pela coleta do leite, para análises em laboratório credenciado, com uma frequência mínima mensal para avaliar parâmetros tais como: teor de gordura, contagem de células somáticas, contagem padrão em placas e resíduos de produtos de uso veterinário. Caso apresentem resultados fora do padrão por 3 meses consecutivos, deve ser interrompido o recolhimento do leite da propriedades [MAPA, 2018, b].

Partindo dos problemas enfrentados pelos produtores, pela indústria e pelos órgãos governamentais responsáveis por garantir a qualidade do leite e seus derivados, este trabalho, norteado pelas questões de pesquisa, tem como objetivo principal identificar alternativas tecnológicas relevantes para o contexto e, a partir destas, propor e avaliar a eficácia de um modelo de sistema computacional, com escalabilidade suficiente para atender um conjunto grande e crescente de produtores, capaz de monitorar (e eventualmente atuar sobre) variáveis relevantes da cadeia produtiva de 
leite em áreas rurais com baixa conectividade de rede e um modelo de baixo custo.

\section{Materiais e Métodos}

Cabe destacar que, para a construção do modelo proposto, foram realizadas visitas a uma propriedade rural, com o objetivo de conhecer as instalações e a rotina do processo de ordenha e recolhimento do leite. O leite ordenhado é enviado para um pré tanque de armazenamento, tendo como função de armazenar uma certa quantidade de leite para então ser enviado para o tanque resfriador de leite. A coleta do leite pelo caminhão tanque é realizada a cada dois dias, correspondendo a quatro ordenhas.

Considerando os requisitos identificados, é proposto um modelo de sistema que visa a coleta automatizada de variáveis na cadeia produtiva de leite, além da disseminação das dados coletadas de cada produtor, envolvendo uma série de produtores de uma determinada região. Pretende-se coletar a temperatura ambiente, umidade ambiente, a temperatura do leite armazenado no tanque de resfriamento, a quantidade de leite armazenado, o consumo de energia elétrica e o $\mathrm{pH}$ do leite, antes que este chegue até o tanque de resfriamento, podendo assim atuar, caso seja identificado uma acidez fora do normal, descartando o mesmo e assim evitando a contaminação do leite já armazenado no tanque de resfriamento.

Os dispositivos fog irão atuar como data smarts agrupando dados de produtores de uma determinada região, bem como servirem de interface de comunicação, por meio de princípios de Vehicular Ad hoc Networks (VANET) e Delay Tolerant Networks (DTN), com uma nuvem computacional na qual são armazenados dados consolidados de todos os produtores, na forma de um data warehouse, permitindo uma visão gerencial global de indicadores de qualidade do sistema de produção.

\section{Conclusão}

O modelo proposto apresenta um instrumento de auxílio, tanto para o produtor como para a indústria, para que sejam monitoradas de forma mais eficiente variáveis relevantes da produção de leite, desde a coleta do leite no tanque de resfriamento localizado no produtor até a chegada do caminhão tanque na indústria.

\section{Referências}

MAPA, 2018. Instrução Normativa No 76, de 26 de novembro de 2018. Disponível em: $\leq$ http://www.in.gov.br/materia/-/asset publisher/Kujrw0TZC2Mb/content/id/ 52750137>. Acessado em: 02 jan. 2019.

MAPA, 2018. Instrução Normativa $\mathrm{N}^{\mathrm{o}}$ 77, de 26 de novembro de 2018. Disponível em: $<$ http://www.in.gov.br/materia/-/asset publisher/Kujrw0TZC2Mb/content/id/ 52750141/do1-2018-11-30-instrucao-normativa-n-77-de-26-de-novembro-de-201852749887>. Acessado em: 02 jan. 2019. 